\title{
ANALISA SISTEM PENGAMAN GENERATOR PLTDG DI PT INDONESIA POWER UNIT PEMBANGKITAN BALI
}

\author{
Putu Wira Asta Dharma ${ }^{1}$, Cok Gede Indra Partha ${ }^{2}$, Ngakan Putu Satriya Utama ${ }^{3}$ \\ ${ }^{123}$ Program Studi Teknik Elektro, Fakultas Teknik, Universitas Udayana \\ Email: wiraasta08@gmail,com ${ }^{1}$, cokindra@unud.ac.id $^{2}{ }^{2}$, ngakansatriya@unud.ac.id $^{-3}$
}

\begin{abstract}
ABSTRAK
Kebutuhan akan tenaga listrik khususnya di Bali setiap tahun terus bertambah, untuk memenuhi permintaan akan tenaga listrik tersebut maka PT Indonesia Power Unit Pembangkitan Bali melakukan penggantian pembangkit PLTD (Pembangkit Listrik Tenaga Diesel) menjadi PLTDG (Pembangkit Listrik Tenaga Diesel Gas). Penggantian pembangkit menyebabkan perubahan kapasitas daya pembangkit sehingga berpengaruh pada setting dan sistem proteksi. Pada penelitian ini bertujuan menganalisa, sistem pengaman relay menggunakan metode simulasi hubung singkat pada program ETAP, untuk menentukan arus gangguan maksimum, minimum, setting waktu kerja dan koordinasi pengaman OCR (Over Current Relay) dan GFR (Ground Fault Relay). Berdasarkan hasil simulasi dan perhitungan didapat OCR sebagai pengaman utama memiliki waktu kerja 1,18 lebih cepat dibandingkan GFR dengan waktu kerja 2,25 detik.
\end{abstract}

Kata Kunci : PLTDG, Hubung Singkat, OCR, GFR

\section{ABSTRACT}

The need for electrical power, especially in Bali, is increasing every year. Therefore, the Bali's Generating Unit of PT Indonesia Power has replaced the Diesel-powered Electrical Generator Pembangkit Listrik Tenaga Diesel (PLTD) with 'the Gas-powered Diesel of Electrical Generator Pembangkit Listrik Tenaga Diesel Gas' (PLTG). Such a replacement causes the change in the generating capacity power which affects the setting and system of protection. This current study was intended to analyze the relay protecting system using the short connecting simulation method in the ETAP program in order to be able to identify the maximum and minimum disturbing current, the working time setting and the OCR (Over Current Relay) and GFR (Ground Fault Relay) protecting coordination. Based on the result of simulation and calculation, it can be concluded that the OCR took 1.18 seconds to work, faster than the GFR, which took 2.25 seconds to work.

Keywords : PLTDG, Short Circuit, OCR, GFR

\section{PENDAHULUAN}

Pembangkit listrik merupakan salah satu bagian penting untuk menyediakan energi listrik bagi kehidupan manusia baik untuk kegiatan industri, kegiatan komersial maupun dalam kehidupan sehari-hari dan rumah tangga yang menggunakan energi listrik. Untuk memenuhi kebutuhan tersebut maka pada PT Indonesia Power Unit Pembangkitan Bali yang menyediakan tenaga listrik khususnya di pulau Bali mengganti pembangkit PLTD mereka menjadi PLTDG yang memiliki kapasitas yang lebih besar, penggantian ini bertujuan untuk meningkatkan dan memperkuat pasokan daya serta efisiensi agar dapat memenuhi kebutuhan energi listrik ke beban. Penggantian pembangkit tersebut menyebabkan berubahnya kapasitas daya pembangkit sehingga berpengaruh pada

setting dan sistem proteksi. Sistem proteksi yang baik haruslah dapat mengamankan gangguan yang menimbulkan kerusakan pada sistem yang dapat menggangu pendistribusian energi listrik ke beban, semakin besar daya pembangkitannya maka semakin besar arus gangguan yang akan terjadi oleh sebab itu diperlukan perhitungan serta analisa agar sistem proteksi dapat bekerja dengan tepat sehingga jika terjadi gangguan overload, over voltage, atau short circuit, maka sistem proteksi dapat bekerja sesuai dengan fungsinya, dimana analisa yang dilakukan ini bertujuan untuk menentukan arus gangguan maksimum 
dan minimum dan setting waktu kerja Over Current Relay (OCR) dan Ground Fault Relay (GFR) pada Pembangkit Listrik Tenaga Diesel Gas di PT Indonesia Power Unit Pembangkitan Bali.

Koordinasi pada sistem proteksi yang baik akan bekerja pada area yang terjadi gangguan agar tidak menyebar ke daerah lainnya, hal ini dapat meningkatkan kinerja pada sistem dengan menjaga kontinuitas suplay daya ke beban. Untuk menjaga dan meningkatkan kinerja pada sistem proteksi perlu dilakuakan suatu penelitian terhadap relay pengaman.

Beberapa penelitian yang membahas tentang setting peralatan proteksi telah banyak dilakukan, salah satunya Penelitian yang menganalisa Setting Relay Gangguan Arus Lebih dan Gangguan Arus Tanah pada Penyulang Topan Gardu Induk Teluk Betung [1]. Analisa ini bertujuan untuk menghitung besar arus hubung singkat dan menentukan setting peralatan proteksi serta membandingkannya dengan setting yang telah terpasang dilapangan agar mendapatansetting yang baik. Penelitian berikutnya membuat analisis terhadap koordinasi relay pengaman (OCR dan GFR) pada PLTU Rembang dengan menggunakan software ETAP 7.0, dari hasil simulasi pada ETAP 7.0 ini digunakan untuk menentukan setting pengaman relay yang didapat dari simulasi dan yang terpasang sekarang, agar mendapatkan setting yang tepat.

Penelitian yang dilakukan ini bertujuan untuk menganalisa sistem pengaman atau proteksi pada generator PLTDG di PT Indonesia Power Unit Pembangkitan Bali menggunakan software ETAP. Analisa yang di lakukan ini di harapkan akan menemukan setting yang tepat pada pengaman generator pembangkit.

\section{KAJIAN PUSTAKA}

\subsection{Proteksi}

Proteksi adalah suatu peralatan yang berfungsi untuk mendeteksi perubahan kondisi pada sistem, memisahkan yang berubah karena terkena gangguan. Untuk membatasi luasnya daerah sistem tenaga yang harus di isolasi bila terjadi gangguan maka sistem proteksi tenaga listrik dibuat secara selektif berdasarkan daerah area proteksinya. Hal penting pada pembagian area proteksi adalah adanya overlap antara dua area yang berdekatan,dengan adanya pembagian area proteksi ini maka pada setiap ganggan yang terjadi di dalam sistem tenaga mejadi wilayah kerja dari alat proteksi utama pada area tersebut. Jika penanganan tersebut tidak berhasil maka diharapkan sistem proteksi pada area yang berdekatan dari proteksi cadangan akan mengambil fungsi pengaman. Agar dapat bekerja dengan baik sebuah sistem proteksi harus memiliki sifat-sifat reliabilitas dimana relay beroperasi seketika ketika diperlukan, kemudian selektivitas serta sensitivitas adalah kemampuan sistem proteksi mengetahui tempat terjadinya gangguan.

\subsection{Gangguan Sistem Tenaga Listrik}

Gangguan yang terjadi pada sistem tenaga listrik secara umum di bagi menjadi 3 kondisi antara lain:

1. Tegangan arus lebih merupakan suatu gangguan sistem tenaga listrik yang tegangan arusnya lebih besar dari yang seharusnya.

2. Beban lebih adalah gangguan yang terjadi akibat konsumsi energi melebihi energi listrik yang telah dihasilkan oleh pembangkit.

3. Hubung singkat merupakan gangguan pada penghantar bertegangan atau penghantar tidak bertegangan secara langsung dan tidak melalui media resistor/beban sehingga terjadi aliran arus yang tidak normal.

\subsection{Sistem Proteksi Relay}

Relay merupakan suatu peralatan yang berupa gulungan yang di beri daya dari sumber DC melalui saklar. Jika terjadi gangguan 1 phase ke tanah relay maka secara otomatis akan memberikan sinyal perintah untuk membuka saklar pemutus tenaga (PMT) agar nantinya bagian yang mengalami gangguan dapat dipisahkan dari sistem yang berada pada kondisi baik. Relay akan dapat mengetahui gangguan dengan mengukur besaran yang diterima seperti tegangan, arus, dan daya. Secara umum fungsi relay yaitu:

1. Mengukur dan menentukan bagian sistem yang mengalami gangguan, kemudian memisahkannya dengan cepat.

2. Meminimalisir pengaruh saat terjadi gangguan pada sistem dan 
mencegah meluasnya gangguan yang terjadi.

3. Mengurangi dampak kerusakan yang lebih parah pada peralatan.

\subsection{Over Current Relay dan Ground Fault Relay}

Over Curent Relay (OCR) bekerja dengan membaca input dari besaran arus kemudian membandingankan dengan nilai setting, kemudian nilai arus yang terbaca oleh relay melebihi nilai setting, maka relay akan mengirim perintah trip (lepas) kepada Pemutus Tenaga (PMT) atau Circuit Breaker (CB). Relay arus lebih OCR memproteksi instalasi listrik terhadap gangguan antar fasa. Sedangkan untuk memproteksi terhadap gangguan fasa ke tanah digunakan relay arus gangguan tanah atau Ground Fault Relay (GFR). Prinsip kerja GFR pada kondisi normal nilai arus sama besar (la,lb.lc), sehingga pada kawat netral tidak timbul arus dan relay GFR tidak dialiri arus,jika terjadi arus yang tidak seimbang atau terjadi gangguan hubung singkat ke tanah maka akan timbul arus urutan nol pada kawat netral, sehingga relay GFR akan bekerja. Prinsip kerja ini hampir sama dengan OCR, yang membedakan hanyalah pada fungsi dan elemen sensor arusnya.

\subsection{Setting Over Current Relay dan Ground Fault Relay}

Kaidah setting relay arus lebih adalah sebagai berikut: Pada zone pengaman relay arus adanya penentuan nilai arus pengaman adalah arus gangguan yang dibawah setting relay yang dihasilkan pada pembangkit atau biasa juga dikatakan arus gangguan minimum, yang dapat dicari dengan rumus:

$$
\begin{aligned}
& \text { Inom }=\frac{p}{\sqrt{3} \times V \times \cos \varphi} \ldots \ldots \ldots \ldots \ldots \ldots \text { (1) } \\
& \mathrm{P} \text { adalah daya beban (Watt) } \\
& \mathrm{V} \text { adalah tegangan saluran (Volt) } \\
& \text { I adalah arus nominal (A) } \\
& \operatorname{Cos} \varphi \text { adalah faktor kerja saluran }
\end{aligned}
$$

Setting arus pada relay umumnya berdasarkan pada hasil arus gangguan. menurut IEC 60255 terdapat beberapa karakteristik relay, yaitu Standard Inverse (SI), Very Inverse (VI) dan Extremely Inverse (EI).

Tabel 1.Karakteristik Relay

\begin{tabular}{|l|c|}
\hline \multicolumn{1}{|c|}{ Karalteristik Relay } & Persamaan IEC 602555 \\
\hline SI / NI = Standard / Normal Inverse & $t=\frac{0,14}{(\text { If } / \text { P.S.M })^{0.02}-1} \times$ TMS \\
\hline VI = Very Inverse & $t=\frac{13.5}{(\text { If } / \text { P.S.M })-1} \times$ TMS \\
\hline EI = Exteremely Inverse & $t=\frac{80}{l_{f}^{2} / P . S . M-1} \times$ TMS \\
\hline LTI = Long Time Invers & $t=\frac{120}{(\text { If } / \text { P.S.M) }-1} \times$ TMS \\
\hline
\end{tabular}

Untuk menentukan setting arus pada relay arus lebih dan gangguan tanah tersebut digunakan rumus P.S.M (Plug Setting Multiplier), sebagai berikut:

$$
\text { P.S.M }=\frac{\text { FaultCurrent }}{\text { CTRasio } \times \text { CurrentSetting }}
$$

dengan nilai current setting 1,05 - 1,1. Setelah diperoleh P.S.M (Plug Setting Multiplier),kemudian menentukan nilai TMS (Time Multiplier Setting) yang di dapat dari data setingan awal ,lalu menentukan waktu kerja relay terhadap gangguan dengan persamaan :

$$
t=\frac{0,14}{(I f / P . S . M)^{0.02}-1} x \text { TMS }
$$

If adalah arus gangguan maksimum

TMS adalah Time Multiplier Setting

\section{METODE PENELITIAN}

Penelitian ini dilakukan di PT Indonesia Power Unit Pembangkitan Bali yang beralamat di jalan di Jalan By Pas Ngurah Rai, Pesanggaran, Denpasar Bali. Jenis data yang digunakan pada penelitian ini adalah data kuantitatif, yaitu data berupa single line diagram generator PLTDG, setting over current relay (OCR) dan setting ground fault relay (GFR) di PT Indonesia Power Unit Pembangkitan Bali, dan data sekunder yang di peroleh dari 
kepustakaan. Analisa pada penelitian ini dilakukan dalam beberapa tahapan sebagai berikut:

1. Pengumpulan data-data teknis berupa single line diagram, data PLTDG unit, data relay yang terpasang pada generator PLTDG, dan data penghantar transmisi $11 \mathrm{kV}$ di PT Indonesia Power Unit Pembangkitan Bali.

2. Menggambar single line diagram yang sesuai dengan data sistem di PT Indonesia Power Unit Pembangkitan Bali menggunakan software ETAP.

\section{HASIL DAN PEMBAHASAN}

Hasil dan pembahasan penelitian yang digunakan ini untuk mencari nilai hubung singkat, waktu kerja, serta koordinasi dari sistem pengaman OCR dan GFR pada generator PLTDG di PT Indonesia Power Unit Pembangkitan Bali.
3. Menganalisa hubung singkat pada bus $11 \mathrm{Kv}$ dengan menggunakan software ETAP.

4. Menghitung waktu kerja dari Over Current Relay (OCR) dan waktu kerja dari Ground Fault Relay (GFR) pada generator PLTDG di PT Indonesia Power Unit Pembangkitan Bali.

5. Menganalisa hasil waktu kerja dari over current relay (OCR) dan waktu kerja dari ground fault relay (GFR) yang di dapat.

6. Mendapatkan kesimpulan.

\subsection{Simulasi Kelistrikan PT Indonesia Power Unit Pembangkitan Bali}

Gambar 1 menunjukan pemodelan single line diagram kelistrikan di PT Indonesia Power Unit Pembangkitan Bali menggunakan software ETAP.

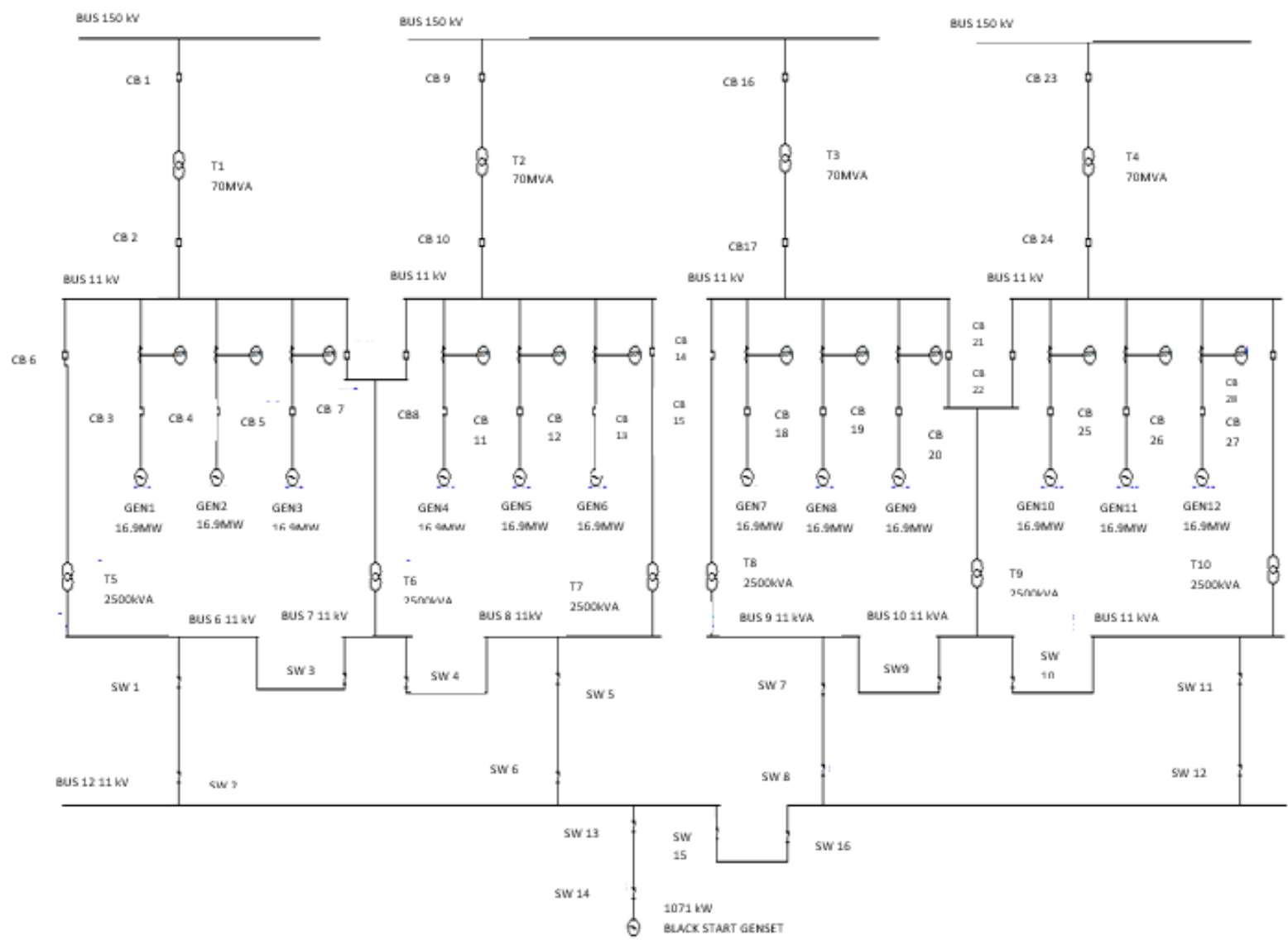

Unit PLTDG memiliki manucfacturer $\mathrm{ABB}$, CB 1 memiliki tipe manucfacturer $\mathrm{ABB}$ 
model class HD4-HXA,CB 2 memiliki manucfacturer $\mathrm{ABB}$ model class HD4HXA/P, Transformator 70 MVA,

Tabel 2. Data PLTDG

\begin{tabular}{|c|c|c|}
\hline Block (Unit) & $\begin{array}{c}\text { Daya } \\
\text { Terpasang }\end{array}$ & $\begin{array}{c}\text { Daya } \\
\text { Mampu }\end{array}$ \\
\hline 1 & $16.9 \mathrm{MW}$ & 16.6 \\
(Unit 1,2,3) & & $\mathrm{MW}$ \\
\hline 2 & $16.9 \mathrm{MW}$ & 16.6 \\
(Unit 4,5,6) & & $\mathrm{MW}$ \\
\hline 3 & $16.9 \mathrm{MW}$ & 16.6 \\
(Unit 7,8,9 & & $\mathrm{MW}$ \\
\hline 4 (Unit & $16.9 \mathrm{MW}$ & 16.6 \\
$10,11,12)$ & & MW \\
\hline Total & 202,8 & 199,2 \\
\hline
\end{tabular}

Pada setiap unit pembangkit ini memiliki spesifikasi yang sama, total daya terpasang sebesar 202,8 MW dan daya mampu 199,2 MW.

Tabel 3. Data Relay Generator PLTDG.

\begin{tabular}{|c|c|c|c|c|c|c|}
\hline No & Unit & Blok & Merk/Tipe & $\begin{array}{c}\text { CT } \\
\text { Rasio }\end{array}$ & $\begin{array}{c}\text { Time } \\
\text { Multiplier } \\
\text { Setting } O C R\end{array}$ & $\begin{array}{c}\text { Time } \\
\text { Multiplier } \\
\text { Setting GFR }\end{array}$ \\
\hline 1 & PLTDG Unit 1 & \multirow{3}{*}{ Blok 1} & \multirow{3}{*}{$\begin{array}{c}\mathrm{ABB} / \mathrm{REG} \\
670\end{array}$} & \multirow{3}{*}{$1250 / 1$} & 1 & 2 \\
\hline 2 & PLTDG Unit 2 & & & & 1 & 2 \\
\hline 3 & PLTDG Unit 3 & & & & 1 & 2 \\
\hline 4 & PLTDG Unit 4 & \multirow{3}{*}{ Blok 2} & \multirow{3}{*}{$\begin{array}{c}\mathrm{ABB} / \mathrm{REG} \\
670\end{array}$} & \multirow{3}{*}{$1250 / 1$} & 1 & 2 \\
\hline 5 & PLTDG Unit 5 & & & & 1 & 2 \\
\hline 6 & PLTDG Unit 6 & & & & 1 & 2 \\
\hline 7 & PLTDG Unit 7 & \multirow{3}{*}{ Blok 3} & \multirow{3}{*}{$\begin{array}{c}\mathrm{ABB} / \mathrm{REG} \\
670\end{array}$} & \multirow{3}{*}{$1250 / 1$} & 1 & 2 \\
\hline 8 & PLTDG Unit 8 & & & & 1 & 2 \\
\hline 9 & PLTDG Unit 9 & & & & 1 & 2 \\
\hline 10 & PLTDG Unit 10 & \multirow{3}{*}{ Blok 4} & \multirow{3}{*}{$\begin{array}{c}\mathrm{ABB} / \mathrm{REG} \\
670\end{array}$} & \multirow{3}{*}{$1250 / 1$} & 1 & 2 \\
\hline 11 & PLTDG Unit 11 & & & & 1 & 2 \\
\hline 12 & PLTDG Unit 12 & & & & 1 & 2 \\
\hline
\end{tabular}

Data relay pada generator yang di dapat dari PT Indonesia Power Unit Pembangkitan Bali memiliki CT Rasio sebesar 1250/1 tipe ABB REG 670.

\subsection{Analisa Hubung Singkat Dengan Software ETAP}

Analisa hubung singkat dapat dicari dengan menentukan besar nilai arus hubung singkat, setelah semua data telah diinputkan, running pada program short circuit analysis. Pemodelan gangguan hubung singkat dengan Software ETAP yang mendapatkan hasil berupa gambar simulasi dan report. bus 2 sebesar $11 \mathrm{kV}$, over current relay terdiri curve type $=\mathrm{B} 1$ - short inverse, Pick up range $=0,04-2,5 \mathrm{sec}$, Pick up $=0,04$, Relay amps, CB3 manucfacturer ABB model class HD4-HXA.

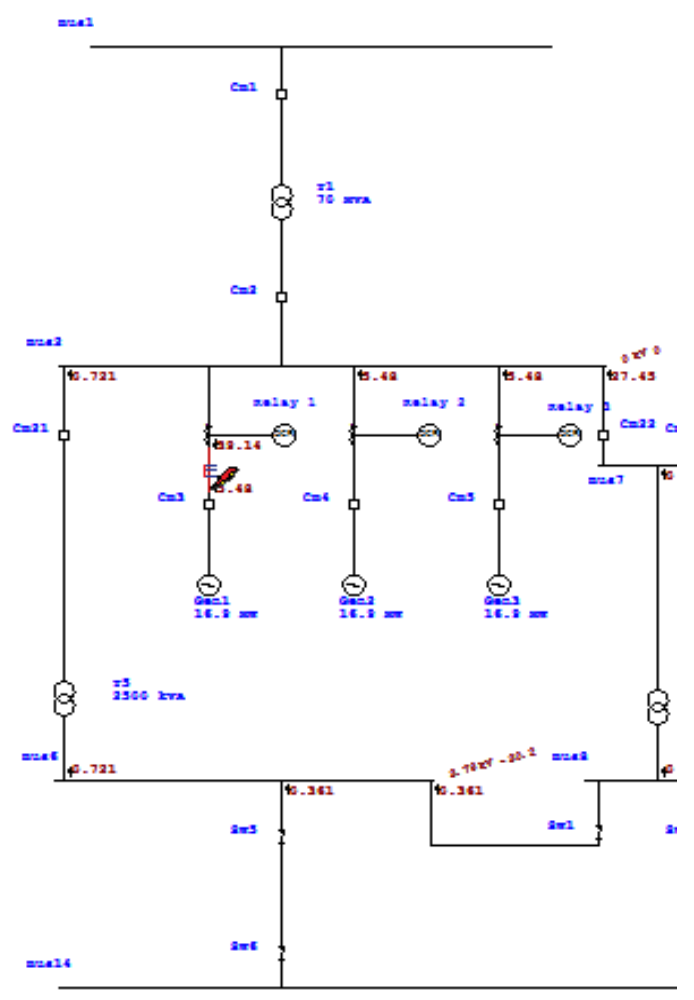

Gambar 2. Simulasi Hubung Singkat Pada Generator PLTDG

Tabel 4. Hasil Running Program Mencari Gangguan Hubung Singkat pada Generator PLTDG. 


\begin{tabular}{|c|c|c|c|c|c|}
\hline \multirow{2}{*}{$\begin{array}{l}\text { From Bus } \\
\text { ID }\end{array}$} & \multirow{2}{*}{$\begin{array}{c}\text { To Bus } \\
\text { ID }\end{array}$} & \multirow{2}{*}{$\begin{array}{c}\% \mathrm{~V} \\
\text { From Bus }\end{array}$} & \multirow{2}{*}{$\begin{array}{c}\mathrm{kA} \\
\text { Symm. rms }\end{array}$} & \multicolumn{2}{|c|}{$\%$ Vottage at Fron } \\
\hline & & & & $v_{2}$ & $\mathrm{vb}$ \\
\hline Bun2 & Toul & 0.00 & 44.623 & 0.00 & 87.53 \\
\hline Bunl & Bun2 & 0.00 & 0.000 & 30.54 & 98.25 \\
\hline Вus & Bus2 & 34.35 & & 61.46 & 62.54 \\
\hline Oen1 & $\mathrm{Bun} 2$ & 100.00 & & 100.00 & 100.00 \\
\hline Oen2 & $\mathrm{Bun} 2$ & 100.00 & 5.485 & 100.00 & 100.00 \\
\hline Gen3 & Bun 2 & 100.00 & & 100.00 & 100.00 \\
\hline Buss & Bus? & 34.35 & & 61,46 & 62.34 \\
\hline Bus17 & Bus3 & 32.55 & 0.567 & 61.79 & 98.57 \\
\hline Burs & Bus 3 & 34.35 & 0.721 & 61.46 & 62.54 \\
\hline Gen 4 & Bus3 & 100.00 & 5.485 & 100.00 & 100.00 \\
\hline Qen5 & Bus3 & 100.00 & 5.485 & 100.00 & 100.00 \\
\hline Gen6 & Bus3 & 100.00 & 5.485 & 100.00 & 100.00 \\
\hline Black Start Genver & Bun14 & 100.00 & 0.228 & 100.00 & 100.00 \\
\hline Burs & Bun13 & 65.10 & 0.646 & 70.27 & 93.25 \\
\hline Bus11 & Bus12 & 65.10 & 0.646 & 70.27 & 93.25 \\
\hline Bust & Bus10 & 65.10 & 0.646 & 70.27 & 93.25 \\
\hline Bust & Bus17 & 65.10 & 0.702 & 70.27 & 93.25 \\
\hline
\end{tabular}

\subsection{Hasil Analisa Hubung Singkat Dengan Software ETAP}

Hasil simulasi gangguan hubung singkat pada PLTDG didapatkan nilai arus gangguan maksimum sebesar 5485 A. Kemudian untuk mencari nilai batas minimum pengaman generator PLTDG PT Indonesia Power Unit Pembangkitan Bali dapat dicari dengan rumus persamaan:

$$
\begin{aligned}
& I_{\text {nom }}=\frac{16900000 \mathrm{~W}}{\sqrt{3} \times 11000 \mathrm{~V} \times 0.85} \\
& I_{\text {nom }}=1042 \mathrm{~A}
\end{aligned}
$$

\subsection{Perhitungan Nilai Setting Over Current Relay}

Nilai setting arus lebih pada generator PLTDG dapat ditentukan dengan mencari arus yang bekerja pada pengaman generator PLTDG tersebut. Nilai arus tersebut, selanjutnya dimasukan ke dalam rumus:

$$
\begin{aligned}
& \text { P.S.M }=\frac{5485}{1250 / 1 \times 1,1} \\
& \text { P.S.M }=4 \mathrm{~A}
\end{aligned}
$$

Fault Current adalah 5485 A

Kemudian untuk menentukan waktu kerja dari Over Current Relay dapat dicari dengan perhitungan:

$$
t=\frac{0.14}{(I f / P . S . M)^{0.02}-1} \times T M S
$$

TMS adalah Time Multiplier Setting

$$
t=\frac{0,14}{(5485 / 4)^{0,02}-1} \times 1
$$

$\mathrm{t}=1,18$ detik

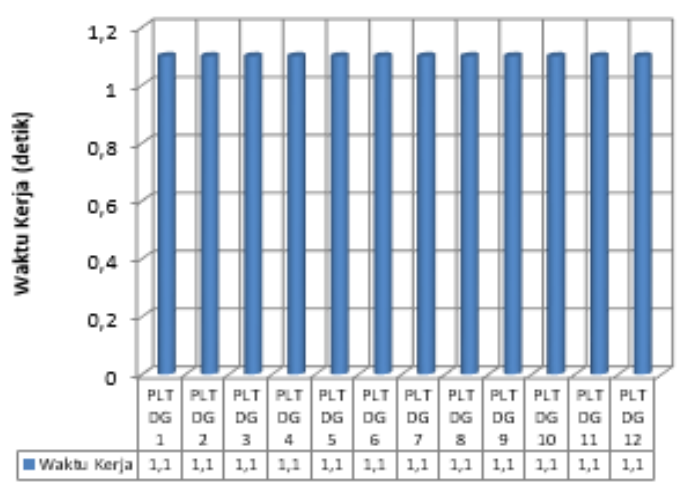

Gambar 3. Grafik Bar Waktu Kerja Over Current Relay

Hasil setting arus OCR (P.S.M) generator PLTDG unit 1 sampai dengan generator PLTDG unit 12 sebesar $4 \mathrm{~A}$. Waktu kerja relay generator PLTDG unit 1 sampai dengan generator PLTDG unit 12 di dapatkan hasil sebesar 1,18 detik.

\subsection{Perhitungan Nilai Setting Ground Fault Relay}

Menentukan nilai setting arus gangguan fasa ke tanah pada generator PLTDG dengan mencari arus gangguan fasa yang bekerja pada pengaman generator PLTDG tersebut, selanjutnya dimasukan ke dalam rumus persamaan (2). Kemudian untuk menentukan waktu kerja dari Ground Fault Relay dapat dicari dengan perhitungan:

$$
t=\frac{0.14}{(I f / P . S . M)^{0.02}-1} \times T M S
$$

$$
\begin{aligned}
& t=\frac{0,14}{(5485 / 4)^{0,02}-1} \times 2 \\
& t=2,25 \text { detik }
\end{aligned}
$$

(3) 


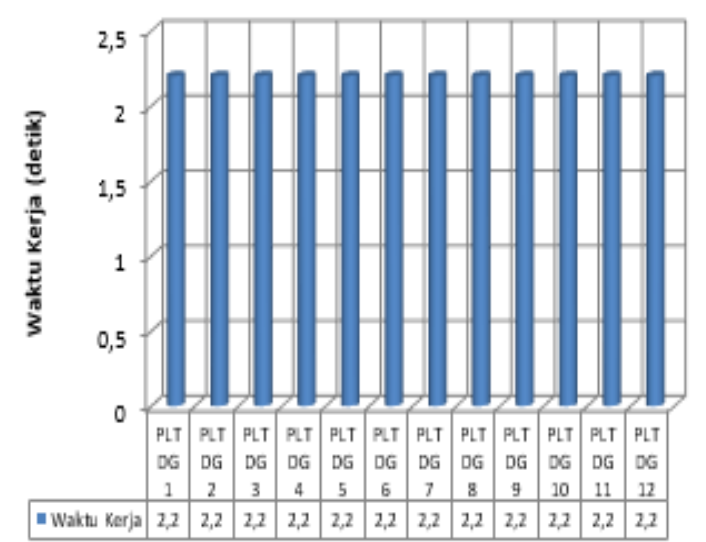

Gambar 4. Grafik Bar Waktu

Kerja Ground Fault Relay

Hasil perhitungan diatas didapatkan waktu kerja relay pada generator PLTDG unit 1 sampai dengan generator PLTDG unit 12 di dapatkan hasil sebesar 2,25 detik.

Koordinasi antara OCR (Over Current Relay) dan GFR (Ground Fault Relay) generator PLTDG di PT Indonesia Power Unit Pembangkitan Bali yang di dapat dengan simulasi ETAP dapat dilihat dari Gambar 5.

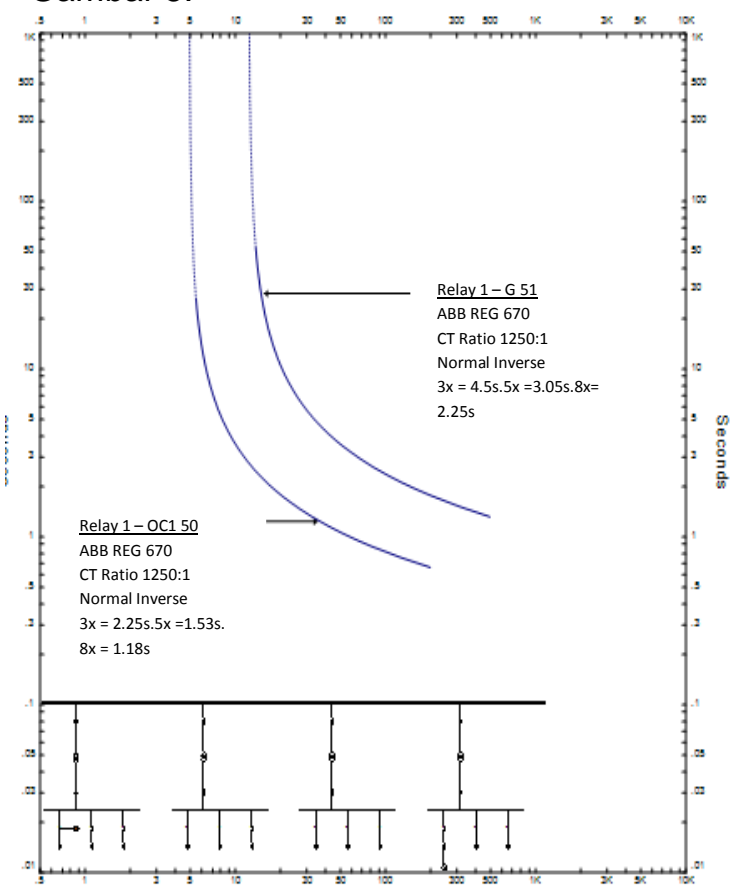

Gambar 5. Grafik Koordinasi

\section{KESIMPULAN}

Hasil perhitungan dan simulasi yang telah di lakukan, maka dapat ditarik kesimpulan waktu kerja dari Over Current Relay pada generator PLTDG unit 1 sampai dengan PLTDG unit 12 sebesar 1,18 detik dan waktu kerja dari Ground Fault Relay pada generator PLTDG unit 1 sampai dengan PLTDG unit 12 sebesar 2,25 detik. Koordinasi relay OCR dan GFR sebagai pengaman sudah sesuai, karena pada grafik tidak menunjukan persilangan garis antara OCR ( Over Current Relay) dengan GFR (Ground Fault Relay)

Relay OCR (Over Current Relay) sebagai pengaman utama memiliki waktu kerja lebih cepat dari pada waktu kerja GFR (Ground Fault Relay) ini di karenakan jika terjadi gangguan yang melebihi arus setting OCR maka GFR memproteksi arus gangguan tersebut dan menghantarkan ke tanah.

\section{DAFTAR PUSTAKA}

[1] A. W. Hidayat, H. Gusmedi, L. Hakim, dan D. Despa, "Analisa Setting Rele Arus Lebih dan Rele Gangguan Tanah pada Penyulang Topan Gardu Induk Teluk Betung," vol. 7, no. 3, hlm. 8, 2013.

[2] B. Pandjaitan, Praktik- Praktik Proteksi Sistem Tenaga Listrik. 2012.

[3] D. Suyitno, Pembangkit Energi Listrik. 2011.

[4] PT Indonesia Power Unit Pembangkitan Bali, Data Single Line Diagram and Relay Protection." 2017.

[5] (Persero) PT PLN, Pedoman Pemeliharaan Proteksi dan Kontrol Penghantar. 2014.

[6] Soman, Power System Protection. 2014.

[7] Y. Triyono, O. Penangsang, S. Anam, dan J. A. R. Hakim, "Analisis Studi jRele Pengaman (Over Current Relay Dan Ground Fault Relay) pada pemakaian distribusi daya sendiri dari PLTU Rembang," hIm. 6, 2013. 